\title{
Effect of Different Methods of Induction on the Mode of Delivery and Fetal Outcome
}

\author{
NABILAAMINU BUHARI, SUMAYYA LUGMAN AHMED, NASTARAN REDHA SOHRABI, HIDAYAT \\ YETUNDE OGUNSOLA, RIWANA B SHAIKH, SHATHAAL SHARBATTI, ELSHEBA MATHEW
}

\begin{abstract}
:
Objectives: To study various methods of induction of labor and their effect on mode of delivery and fetal outcome.

Methods: 104 pregnant women induced in Gulf Medical College hospital from August to November 2009 were included. Mothers were observed from the start of their induction and followed up till they were discharged. The methods of induction compared were the use of prostaglandin, oxytocin, prostaglandin and oxytocin combined and artificial rupture of membranes.
\end{abstract}

Results: Out of 104 pregnant women, 86 (89\%) had normal vaginal delivery. Of these, 36 (41.9\%) were induced with combination of prostaglandin and oxytocin, 32 (37.2\%) with prostaglandin, 14 (16.2\%) with oxytocin, and 4 (4.6\%) with artificial rupture of membranes. 13 (12.5\%) mothers delivered through caesarean section of these, 7 (53.8\%) mothers were induced with prostaglandin, 3 (23\%) with prostaglandin and oxytocin, 2 (15.3\%) with oxytocin alone, and $1(7.7 \%)$ with artificial rupture of membranes. Induction of labor with combination of prostaglandin and oxytocin was found to be the most effective method. Duration of labor between primigravidas and multigravidas were significantly different with primigravidas having longer duration of labor with mean time of 12.47 hours while multigravidas had 9.16 hours.

Conclusion: Induction of labor with combination of prostaglandin and oxytocin was found to be the most effective method in this study with very good progressing to normal vaginal delivery. Further research is needed on a larger scale to compare other methods of labor induction on parturient to be able to recommend the most effective method of labor induction.

Keywords: Induction of labor, Mode of delivery, Fetal outcome.

\section{Introduction:}

Induction of labor refers to iatrogenic stimulation of uterine contractions to accomplish delivery prior to the onset of spontaneous labor ${ }^{1}$. It is also defined as progressive change in the uterine cervix in response to repetitive uterine contractions. Labor can be spontaneously augmented or artificially induced ${ }^{2}$. It is performed when the risks to the fetus and/or the mother outweighs those of bringing the pregnancy to an end ${ }^{3}$. The goal of induction of labor is to achieve vaginal delivery through cervical dilation and uterine contractions prior to the onset of spontaneous labor. This is to be distinguished from augmentation of labor, which is the assistance of cervical dilation and or uterine contractions after labor has been diagnosed. The benefit of induction of labor is that a trial for vaginal delivery is possible, when delivery is indicated. Without an attempt at induction, cesarean delivery is the only alternative if delivery must be performed prior to the onset of labor ${ }^{4}$. The primary indications for induction of labour are post-term (prolonged pregnancies), premature rupture of membranes (PROM), artificial rupture of membrane (ARM), maternal hypertension, and rarely fetal death.

According to the most current studies, the rate varies from $9.5 \%$ to $33.7 \%$ of all pregnancies annually. In the absence of a ripe or favorable cervix, a successful vaginal birth is less likely ${ }^{5}$. Since, around $20 \%$ of all deliveries are preceded by labor induction, a proportion that has not varied dramatically over recent years; this issue is of great importance ${ }^{6}$. Most methods of inducing labour before the last half century involved mechanical 
manipulations, including Galvinism, repeated pressurised douches, extra-amniotic aqua picea, tents, bougies and catheters. The administration of castor oil, quinine and posterior pituitary extract were also utilized ${ }^{5}$. Induction of labour was traditionally performed by ARM. In mid 1950s synthetic oxytocin became available and was then used as an intravenous adjunct after ARM. In favorable cases, this would succeed in inducing labour and often in effecting vaginal delivery. However in unfavorable cases it was not successful and sometimes was impossible to rupture membrane. In late 1960s prostaglandin became available, various routes and preparation been used but the most common formulation in current use is inserted vaginally into the posterior fornix as a tablet or gel ${ }^{3}$.

All of the above stated methods were extremely detrimental towards the health of both the mother and the fetus. Therefore, as we crossed the threshold of the twenty first century, the methods of induction of labor changed drastically. Currently, two different approaches to labour induction are used, often in combination: one relies upon pharmacological agents to modify cervical form with or without stimulating uterine contractions, and the other uses mechanical stimulation to provoke cervical effacement, dilatation and ultimately uterine contractions ${ }^{5}$.

Even today there is significant scope for study in this field. Therefore, we have chosen to base our research upon the present methods of labor induction. The present study was conducted to investigate the type of labor induction methods practiced, the reasons for labor induction, know the effect of various methods of labor induction on the mode of delivery, compare the duration of labor between multigravida and primigravida mothers after induction, investigate the fetal outcome in the different methods of labor induction and to identify the induction regimen with the most favorable maternal and fetal outcome in Gulf Medical College Hospital and Research Centre (GMCHRC), Ajman, United Arab Emirates (UAE).

\section{Materials and Methods:}

A Record based descriptive study was conducted in Gulf Medical College Hospital and Research Centre, Ajman. Pregnant women who had induction of labour formed the study sample and sample size was 100 . The proforma for data collection included variables that should be considered when assessing the outcome of an induced pregnancy. It was divided into (a) demographic variables like age and ethnicity of the mother, gender of the infant, booked/unbooked case; (b) the maternal factors such as ante natal care, gravidity status, past medical complications, reason for induction, method of induction, maternal complications of induction, fetal complications of induction; and (c) fetal factors such as Apgar score, need for resuscitation/admission to ICU, development of neonatal jaundice and variables. In 65 cases data was collected from the patients and their records in the wards. We collected information from them in the first stage of labor at the beginning of their induction about their past medical history, past pregnancy, past maternal complication, previous induced pregnancy, if yes what method was used. Information was also collected from their files about their recent induction and what was used. We collected the data for another 39 cases from the records of induced mothers identified from the labour room log book. After the collection of data, the data entry was done in the Microsoft excel which was later decoded using PASW 17.0 version. Data was presented mainly as percentages, to test associations chi square test was done and to test the difference between two means' $t$ ' test was used. The graphs and figures were constructed according to the obtained information.

\section{Results:}

Out of 104 patients taken into the study majority were from Indian subcontinent and the least was from Arab continent. Most mothers were above the age of 25 years. Only one of them was less than 20 years and none over 40 years.

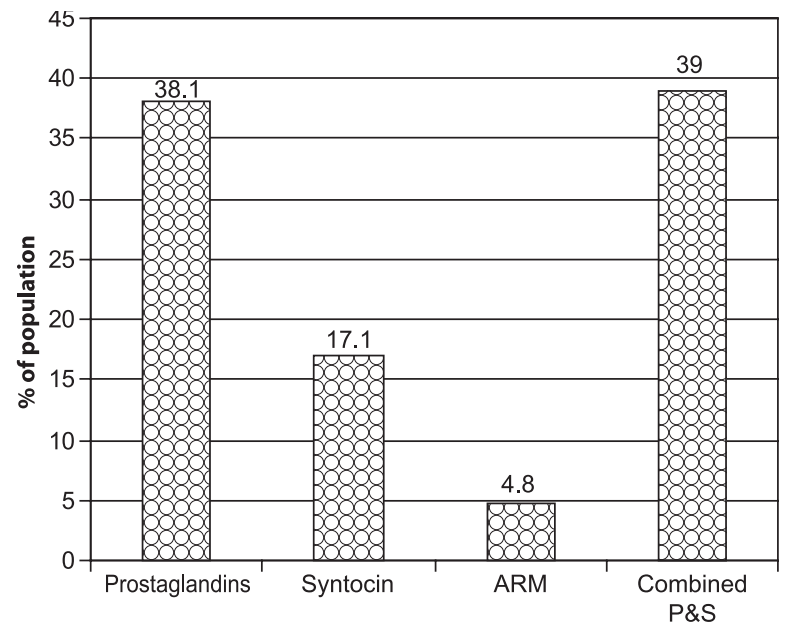

Fig.-1: Comparison of methods of induction $(n=104)$ 
The bar chart shows the frequency of different methods of labour used in GMC hospital when inducing patients, as shown the most common method is the combination of oxytocin with prostaglandin while the second most common is prostaglandins alone.

The response of pregnant women to induction shows that the number of patients who agreed immediately are greater in number than the women that needed convincing or done by her request. This tells that induction of labor is widely accepted by women who were induced in GMCHRC.
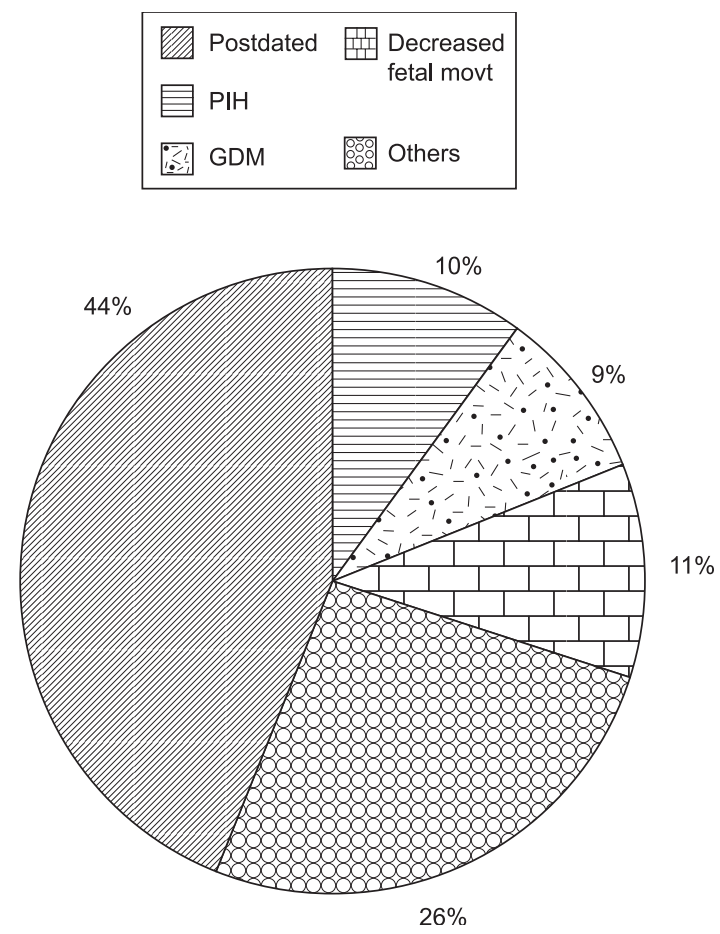

Fig.-2: Reasons for Inducing Labor ( $n=104)$
The chart shows the different reasons for which women in GMC hospital were induced. Induction of labor has various indications as shown above, 'others' include: urinary tract infection, leakage per vagina, premature rupture of membrane. The statistical data shows that major systemic diseases may lead to induction of labor. The study has shown that there is no significant effect of induction of labor on neonatal jaundice.

The table shows the different methods of induction and their effect on the mode of delivery. Out of the total 104 induced patients, 86 went for vaginal delivery which suggests a good prognosis, the combined method having the best rate, followed by prostaglandins alone. Combined Prostaglandin \& Syntocin has the highest rate, with ARM having the lowest. Clearly there is no definite association between the methods used and the development of neonatal jaundice.

A significant number of pregnant women had complication during pregnancy and that might be the reason for their induction. An independent't' test showed there is a statistically significant association between mean duration of labor among Primigravida and Multigravida $(p<0.01)$.

In This study, majority of the mothers were Multigravida and when compared to primigravida, they had shorter duration of labour.

The table shows the relationship between complicated pregnancies and the mode of delivery. The most common complications encountered included diabetes mellitus and pregnancy induced hypertension (PIH) and others. Others include heart problems and urinary tract infection. Even though these complications were the reason of induction in many cases, they do not have any significant role in determining the mode of delivery.

The table examines the effect of the neonatal weight in relation to their stay in I.C.U. It shows that the neonatal weight has no significant effect on their stay in ICU.

Table-I

Different method of induction and mode of delivery

\begin{tabular}{|c|c|c|c|c|c|c|c|}
\hline \multirow[t]{2}{*}{ Method of induction } & \multicolumn{2}{|c|}{ Vaginal } & \multicolumn{2}{|c|}{ Instrumental } & \multicolumn{2}{|c|}{ Cesarean Section } & \multirow[t]{2}{*}{ Total } \\
\hline & No. & $\%$ & No. & $\%$ & No. & $\%$ & \\
\hline Prostaglandins & 32 & 80 & 1 & 2.5 & 7 & 17.5 & 40 \\
\hline Syntocin & 14 & 77.7 & 2 & 11 & 2 & 11 & 18 \\
\hline ARM & 4 & 80 & 0 & - & 1 & 20 & 5 \\
\hline Combination of first two & 36 & 90 & 1 & 2.5 & 3 & 7.5 & 40 \\
\hline
\end{tabular}


Table-II

Effect of complication during pregnancy on the mode of delivery

\begin{tabular}{lccccccc}
\hline Complication & \multicolumn{3}{c}{ Mode of Delivery } & \multicolumn{2}{c}{ Total } \\
\cline { 2 - 6 } & \multicolumn{2}{c}{ Vaginal } & \multicolumn{2}{c}{ Instrumental } & \multicolumn{2}{c}{ C/Section } & \\
\hline Diabetes & 7 & $(100 \%)$ & 0 & 0 & 0 & 0 & 7 \\
Hypertension & 11 & $(85 \%)$ & 0 & 0 & 2 & $(15 \%)$ & 13 \\
Others & 5 & $(50 \%)$ & 1 & $(10 \%)$ & 4 & $(40 \%)$ & 10 \\
No complication & 63 & $(86 \%)$ & 3 & $(4 \%)$ & 7 & $(10 \%)$ & 73 \\
\hline
\end{tabular}

Table-III

Weight of neonates and their stay in ICU

\begin{tabular}{lcccccc}
\hline Weight & \multicolumn{5}{c}{ Intensive care Unit } & Total \\
\cline { 2 - 5 } & ICU & \multicolumn{3}{c}{ No ICU } & 2 & $(3 \%)$ \\
\cline { 2 - 5 } 2 & 1 & $(50 \%)$ & 1 & $(50 \%)$ & 21 & $(20 \%)$ \\
3 & 3 & $(14 \%)$ & 18 & $(86 \%)$ & 76 & $(73 \%)$ \\
4 & 13 & $(17 \%)$ & 63 & $(83 \%)$ & 4 & $(4 \%)$ \\
\hline
\end{tabular}

\section{Discussion:}

The present study compares the effects of different methods of labor induction on the mode of delivery and the fetal outcome. Majority of the mothers were Indians, booked, multigravida and were less than 30 years of age. The fetal factors were gender, weight, apgar score, birth trauma, fetal distress and neonatal jaundice. Most of the neonates had a good apgar score and the mean weight was $3 \mathrm{~kg}$. The duration of labor for primigravidas is significantly longer than multigravida. This is consistent with previous researches done on this topic. The methods of induction we studied were prostaglandin, oxytocin and ARM. Our research shows that use of Vaginal Prostaglandin E2 in labor induction was very effective leading to increased successful vaginal delivery. Previous research support this, such as the original randomized controlled studies comparing PGE2 and placebo for induction when the cervix was unfavorable showed dramatic reductions in the rates of failed inductions, prolonged labors, and delivery by caesarean section when prostaglandins were used. There were no increase in the operative delivery rates and significant improvements in cervical favorability within 24 to 48 hours $^{7}$.

However, the use of oxytocin is also very effective but from this research, better outcomes found with prostaglandins. Study done with oxytocin shows that the patients received the traditional oxytocin regimen underwent more cesarean sections. The findings of the present study shows that continuous low-dose oxytocin infusion is effective in inducing labor and achieving vaginal delivery, and it is associated with a lower incidence of over stimulation of the uterus. This explains the fact that low infusion over a longer period of time is a better method of oxytocin administration ${ }^{8}$. Recent study shows that concurrent vaginal prostaglandin and intravenous oxytocin for labor induction of term PROM did not expedite delivery or improve patient satisfaction ${ }^{9}$. The use of both prostaglandin and oxytocin for labor induction were studied in our research and we have found that this method was associated with a higher number of successful vaginal deliveries. Hence, further research is needed on this aspect to understand more on the efficacy of combined prostaglandin and oxytocin in the induction of labor. The main reason for induction of labor was post dated pregnancy which is consistent with other researches ${ }^{10}$. Most of the mothers progressed to normal vaginal deliveries and only few progressed to caesarean section.

\section{Conclusion:}

Most common reason for the induction of labour was the mothers are postdated or due to medical conditions 
and for mother's convenience. The duration of labour differs significantly with parity, multigravidas having shorter duration. The maternal and fetal outcomes are good with labor induction. The most effective method of induction is the use of combined prostaglandin and oxytocin, associated with a higher success rate than when used alone and is more effective in multiparous than in primigravida.

\section{References:}

1. De Ribes C. De l'Accouchement Provoque, Dilatation du Canal Genital a l'Aide de Ballons Introduits dans la Cavite Uterine Pendant la Grossesse. Paris, Steinheil, 1988.

2. Ashford, J. I. A History of Accouchement Forcé: 1550-1985. Birth 1986;13: 241-249. doi: 10.1111/j.1523-536X.1986.tb01055.x.

3. Graham H. Eternal Eve: The History of Gynecology and Obstetrics. London, T. Brun, 1950.
4. Denman T. An Introduction to the Practice of Midwifery. London, J. Johnson, 1794.

5. Eden TW. Review: AManual of Midwifery. Lancet 1912;1:1064.

6. Dale HH. On some physiological actions of ergot. J Physiol 1906;34:163-206.

7. Theobald GW. The use of posterior pituitary extracts in physiological amounts in obstetrics. BMJ 1948;11:123-7.

8. Amazing Pregnanacy [Online]. Sophia Levis: What is a Bishop's Score and How Does it Relate to Inducing Labor [cited 2010 October 17]. Available from URL: http:// www.amazing pregnancy.com/pregnancyarticles/173.html.

9. Mary L, Day BJ, Snell. Use of prostaglandins for induction of labor. J Nurse-Midwifery 1993;38(2):S42-48.

10. Stubbs TM, Oxytocin for labor induction. Clin Obstet Gynecol 2000;43(3):489-94. 